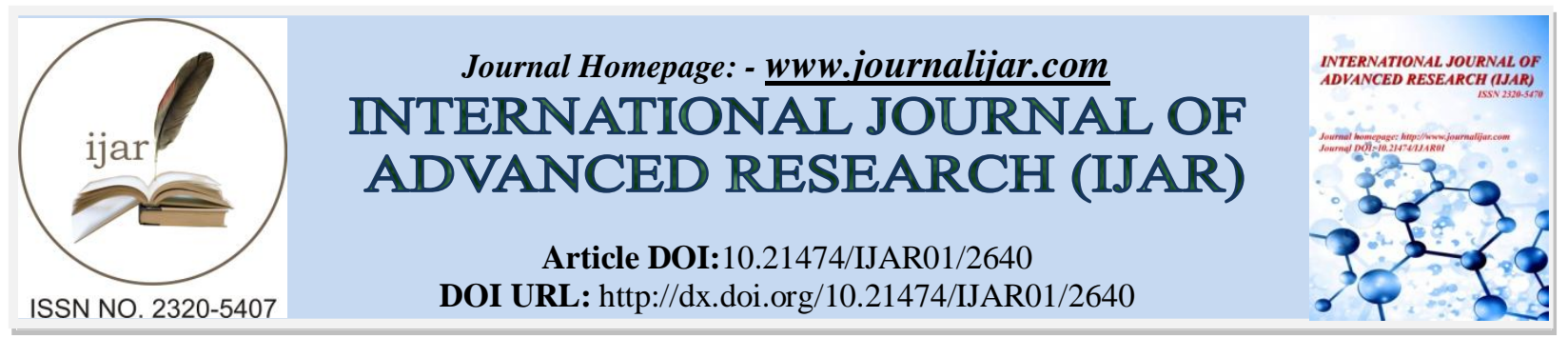

RESEARCH ARTICLE

\title{
ESTIMATION OF MEAN TIME TO RECRUITMENT FOR A TWO GRADED MANPOWER SYSTEM WITH TWO THRESHOLDS, DIFFERENT EPOCH FOR EXITS AND EXPONENTIAL INTER- DECISIONS UNDER CORRELATED WASTAGE.
}

\author{
L. Saral ${ }^{1}$, S. Sendhamizh Selvi ${ }^{1}$ and A. Srinivasan ${ }^{2}$.
}

1. PG and Research Department of Mathematics, Government Arts College, Tiruchirappalli-22, TN, India.

2. PG and Research Department of Mathematics, Bishop Heber College, Tiruchirappalli -17,TN, India.

\section{Manuscript Info}

\section{Manuscript History}

Received: 30 October 2016

Final Accepted: 29 November 2016

Published: December 2016

Key words:-

Two graded manpower system, decision and exit epochs, ordinary renewal process, univariate policy of recruitment with two thresholds, mean time to recruitment.

\section{Abstract}

In this paper, an organization with two grades, subjected to exit of personnel due to policy decisions taken by the organization is considered. As the exit of personnel is unpredictable a univariate recruitment policy involving two thresholds one is optional and other is mandatory is suggested to enable the organization to plan its decision on recruitment. Assuming that the policy decisions and exits occur at different epochs, a stochastic model is constructed and the mean time to recruitment is obtained when the loss of manpower at each decision epoch are identically distributed constantly correlated and exchangeable exponential random variables, thresholds follows independent and identically distributed exponential random variables, the inter-policy decision times form independent and identically distributed exponential random variable and inter-exit times form an ordinary renewal process.

Copy Right, IJAR, 2016,. All rights reserved.

\section{Introduction:-}

Attrition is common phenomenon in many organizations. This leads to the depletion of manpower. Recruitment on every occasion of depletion of manpower is not advisable since every recruitment involves cost. Hence the cumulative depletion of manpower is permitted till it reaches a level, called the threshold. If the total loss of manpower exceeds this threshold, the activities in the organization will be affected and hence recruitment becomes necessary. In [1],[2],[6] \& [7] the authors have discussed the manpower planning models by Markovian and renewal theoretic approach. In [8],[9] the author has studied the problem of time to recruitment for a single grade manpower system and obtained the variance of the time to recruitment when the loss of manpower forms a sequence of independent and identically distributed random variables, the inter-decision times form a geometric process and the mandatory breakdown threshold for the cumulative loss of manpower is an exponential random variable by using the univariate cum policy of recruitment. In [5] the author has initiated the study of the problem of time to recruitment for a single grade manpower system by incorporating alertness in the event of cumulative loss of manpower due to attrition crossing the threshold, by considering optional and mandatory threshold for the cumulative loss of manpower in this manpower system. In [15] the author has studied the problem of time to recruitment for a two graded manpower system, by considering optional and mandatory thresholds. In [10] the author has studied the problem of time to recruitment for a two graded manpower system, by considering optional and mandatory thresholds using different types for inter-decision times.

Corresponding Author:-L.Saral.

Address:-PG and Research Department of Mathematics, Government Arts College, Tiruchirappalli-22,

$\mathrm{TN}$, India. 
In all the above cited work, it is assumed that attrition takes place instantaneously at decision epochs. This assumption is not realistic as the actual attrition will take place only at exit points Which may or may not coincide with decision points. This aspect is taken into account for the first time in [3]\&[4] the author has studied the problem of variance of time to recruitment is obtained when inter-decision times and exit times are independent and identically distributed exponential random variables using univariate policy for recruitment and Laplace transform in the analysis. In [11],[12] the author has studied the work in [3],[4] by considering optional and mandatory thresholds which considering non-instantaneous exits at decision epochs. In [6],[7] the author has to find mean time to recruitment for a two graded manpower system associated with a univariate policy of recruitment involving single threshold. . Recently, in [13],[14] the author has studied the work in [6],[7] by considering optional and mandatory thresholds which considering non-instantaneous exits at decision epochs.

In the present paper, for a two graded manpower system, a mathematical model is constructed in which attrition due to policy decision take place at exit points and there are optional and mandatory thresholds as control limits for the cumulative loss of manpower. A univariate policy of recruitment based on shock model approach is used to determine the expected time to recruitment when the system has different epochs for policy decisions and exits and the inter-decision times forms independent and identically distributed exponential random variable and loss of manpower follows constantly correlated exchangeable and exponential random variable.

\section{Model Description:-}

Consider an organization taking decisions at random epochs in $(0, \infty)$ and at every decision making epoch a random number of persons quit the organization. There is an associated loss of manpower if a person quits. It is assumed that the loss of manpower is linear and cumulative.

$X_{i} \quad$ - the continuous random variable representing the amount of depletion of manpower (loss of man hours) caused at the $i^{\text {th }}$ exit point . $X_{\mathrm{i}}$ 's are identically distributed and constantly correlated exchangeable and exponentialrandom variable with density function $\mathrm{m}($.$) , distribution function \mathrm{M}($.$) \& Mean 1 / \alpha ; \alpha>0$.

$\mathrm{S}_{\mathrm{k}} \quad$ - the total loss of manpower upto the first $\mathrm{k}$ exit points.

$\rho$ - the correlation between $X_{i}$ and $X_{j}$ where $i \neq j$.

$U_{j}$ - continuous random variable representing the time between $(j-1)^{\text {th }}$ and $j^{\text {th }}$ policy decisions. It is assumed that's

$\mathrm{U}_{\mathrm{j}}$ 's are independent and identically distributed random variables with probability density function $\mathrm{f}($.$) ,$ distribution function $\mathrm{F}($.).

$\mathrm{W}_{\mathrm{k}}$ - the continuous random variable representing the time between the $(\mathrm{k}-1)^{\text {th }}$ and $\mathrm{k}^{\text {th }}$ exit times. It is assumed that $\mathrm{W}_{\mathrm{k}}$ 's are independent and identically distributed random variables with probability density function $\mathrm{g}($.$) ,$ probability distribution function $\mathrm{G}($.)

$\mathrm{N}_{\mathrm{e}}(\mathrm{t})$ - the number of exits points lying in $(0, \mathrm{t}]$

$\mathrm{Y}_{\mathrm{A}}, \mathrm{Y}_{\mathrm{B}}\left(\mathrm{Z}_{\mathrm{A}}, \mathrm{Z}_{\mathrm{B}}\right)$. the exponential random variable denoting the optional (mandatory) thresholds for grade $\mathrm{A}$ and $\mathrm{B}$ with distribution function $\mathrm{H}\left(\right.$.), and density function $\mathrm{h}\left(\right.$.) and mean $\frac{1}{\lambda_{A}}, \frac{1}{\lambda_{B}}\left(\frac{1}{\mu_{A}}, \frac{1}{\mu_{B}}\right)$ respectively, where

$\lambda_{\mathrm{A}}, \lambda_{\mathrm{B}},\left(\mu_{A}, \mu_{B}\right)$ are positive. Assume that $\mathrm{Y}_{\mathrm{A}}<\mathrm{Z}_{\mathrm{A}} \& \mathrm{Y}_{\mathrm{B}}<\mathrm{Z}_{\mathrm{B}}$.

$p \quad$ - the probability that the organization is not going for recruitment when optional threshold is exceeded by thecumulative loss of manpower.

$q \quad$ - the probability that every policy decision has exit of personnel. (q $\neq 0)$.

$\mathrm{T}$ - the random variable denoting the time to recruitment with distribution function $\mathrm{L}($.) , density function $1($.$) ,$ mean $\mathrm{E}(\mathrm{T})$

$\bar{a}($.$) - the Laplace transform of a(.).$

The univariate CUM policy of recruitment employed in is paper is stated as follows.

Recruitment is done whenever the cumulative loss of man hours in the organization exceeds the the mandatory threshold. The organization may or may not go for recruitment if the cumulative loss of man hours exceeds the optional threshold. 


\section{Main Result:-}

$\mathrm{P}(\mathrm{T}>\mathrm{t})=\mathrm{P}\{$ Total loss of manpower at the exit points in $(0, \mathrm{t}]$ does not exceed $\mathrm{Y}$ or the total loss of manpower at the exit points in $(0, \mathrm{t}]$ exceeds $\mathrm{Y}$ but lies below $\mathrm{Z}$ and the organization is not making recruitment $\}$

$$
\begin{aligned}
& P(T>t)=P\left(S_{N_{e}(t)} \leq Y\right)+P\left(Y<S_{N_{e}(t)} \leq Z\right) p \\
& P(T>t)=\sum_{k=0}^{\infty} P\left[N_{e}(t)=k\right] P\left(S_{k}<Y\right)+p \sum_{k=0}^{\infty} P\left[N_{e}(t)=k\right] P\left(S_{k}>Y\right) P\left(S_{k} \leq Z\right)
\end{aligned}
$$

From Renewal theory:-

$P\left\{N_{e}(t)=k\right\}=G_{k}(t)-G_{k+1}(t)$ and $G_{0}(t)=1$

From (1), we get

$\mathrm{P}(\mathrm{T}>\mathrm{t})=\sum_{k=0}^{\infty}\left\{G_{k}(t)-G_{k+1}(t)\right\} P\left\{S_{k} \leq Y\right\}+p \sum_{k=0}^{\infty}\left\{G_{k}(t)-G_{k+1}(t)\right\} P\left\{S_{k}>Y\right\} P\left\{S_{k} \leq Z\right\}$

Since $X_{i}$ 's are assumed to be identical constantly correlated and exchangeable exponential random variable with parameter $\alpha$, Cumulative distribution of the partial sum is given in 1955, Gurland [7],

$G_{k}(y)=(1-\rho) \sum_{i=0}^{\infty} \frac{(k \rho)^{i} \phi(k+i, y / b)}{(1-\rho+k \rho)^{i+1}(k+i-1) !} \quad$ where $\phi(k+i, y / b)=\int_{0}^{y / b} e^{-z} z^{k+i-1} d z, \mathrm{~b}=\alpha(1-\rho)$ and $\rho$ is the constant correlation between $\mathrm{X}_{\mathrm{i}}$ and $\mathrm{X}_{\mathrm{j}} ; \mathrm{i} \neq \mathrm{j}$.

$P\left(S_{k}<Y\right)=\int_{0}^{\infty} G_{k}(y) h(y) d y---(5)$

Case- (i):

$\mathrm{Y}=\max \left(\mathrm{Y}_{\mathrm{A}}, \mathrm{Y}_{\mathrm{B}}\right) \& \mathrm{Z}=\max \left(\mathrm{Z}_{\mathrm{A}}, \mathrm{Z}_{\mathrm{B}}\right)$.

$\mathrm{Y}=\max \left(\mathrm{Y}_{\mathrm{A}}, \mathrm{Y}_{\mathrm{B}}\right)$ Where $\mathrm{Y}_{\mathrm{A}}, \mathrm{Y}_{\mathrm{B}}$ are independent and identically distributed exponential random variable with mean $\frac{1}{\lambda_{A}} \& \frac{1}{\lambda_{B}}$ respectively, and the probability density function $\mathrm{h}(\mathrm{y})$ of $\mathrm{Y}$ is given by

$h(y)=\lambda_{A} e^{-\lambda_{A} y}+\lambda_{B} e^{-\lambda_{B} y}-\left(\lambda_{A}+\lambda_{B}\right) e^{-\left(\lambda_{A}+\lambda_{B}\right) y}$

Using (4) \& (6) in (5),

$$
\begin{aligned}
& P\left(S_{k}<Y\right)=\int_{0}^{\infty}(1-\rho) \sum_{i=0}^{\infty} \frac{(k \rho)^{i} \phi\left(k+i,,^{y} / b\right)}{(1-\rho+k \rho)^{i+1}(k+i-1) !}\left[\lambda_{A} e^{-\lambda_{A} y}+\lambda_{B} e^{-\lambda_{B} y}-\left(\lambda_{A}+\lambda_{B}\right) e^{-\left(\lambda_{A}+\lambda_{B}\right) y}\right] d y \\
& P\left(S_{k}<Y\right)=(1-\rho)\left[A_{1 k}+A_{2 k}-A_{3 k}\right]--(7) \\
& P\left(S_{k} \geq Y\right)=1-\left\{(1-\rho)\left[A_{1 k}+A_{2 k}-A_{3 k}\right]\right\}--(8)
\end{aligned}
$$

Proceeding as in the deviation of $\mathrm{z}$, we find that

$$
P\left(S_{k}<Z\right)=(1-\rho)\left[A_{4 k}+A_{5 k}-A_{6 k}\right]---(9)
$$

Where $A_{1 k}=\frac{1}{\left(b \lambda_{A}+1\right)^{k-1}\left[(1-\rho+k \rho)\left(b \lambda_{A}+1\right)-k \rho\right]}, A_{2 k}=\frac{1}{\left(b \lambda_{B}+1\right)^{k-1}\left[(1-\rho+k \rho)\left(b \lambda_{B}+1\right)-k \rho\right]}$,

$$
\begin{aligned}
& A_{3 k}=\frac{1}{\left(b\left(\lambda_{A}+\lambda_{B}\right)+1\right)^{k-1}\left[(1-\rho+k \rho)\left(b\left(\lambda_{A}+\lambda_{B}\right)+1\right)-k \rho\right]}, \\
& A_{4 k}=\frac{1}{\left(b \mu_{A}+1\right)^{k-1}\left[(1-\rho+k \rho)\left(b \mu_{A}+1\right)-k \rho\right]}, A_{5 k}=\frac{1}{\left(b \mu_{B}+1\right)^{k-1}\left[(1-\rho+k \rho)\left(b \mu_{B}+1\right)-k \rho\right]}, \\
& A_{6 k}=\frac{1}{\left(b\left(\mu_{A}+\mu_{B}\right)+1\right)^{k-1}\left[(1-\rho+k \rho)\left(b\left(\mu_{A}+\mu_{B}\right)+1\right)-k \rho\right]},
\end{aligned}
$$


Using (7), (8) \& (9) in (3) becomes,

$$
\begin{aligned}
& P(T>t)=\sum_{k=0}^{\infty}\left\{G_{k}(t)-G_{k+1}(t)\right\}(1-\rho)\left[A_{1 k}+A_{2 k}-A_{3 k}\right] \\
& +p \sum_{k=0}^{\infty}\left\{G_{k}(t)-G_{k+1}(t)\right\}\left[1-\left\{(1-\rho)\left[A_{1 k}+A_{2 k}-A_{3 k}\right]\right\}\right]\left[(1-\rho)\left[A_{4 k}+A_{5 k}-A_{6 k}\right]\right]--
\end{aligned}
$$

Now,

$\mathrm{L}(\mathrm{t})=1-\mathrm{P}(\mathrm{T}>\mathrm{t})$

$$
\begin{aligned}
L(t)= & -(1-\rho)\left\{\sum_{k=0}^{\infty}\left\{G_{k}(t)-G_{k+1}(t)\right\}\left[A_{1 k}+A_{2 k}-A_{3 k}\right]+p \sum_{k=0}^{\infty}\left\{G_{k}(t)-G_{k+1}(t)\right\}\left[A_{4 k}+A_{5 k}-A_{6 k}\right]\right. \\
& \left.-p(1-\rho) \sum_{k=0}^{\infty}\left\{G_{k}(t)-G_{k+1}(t)\right\}\left[A_{1 k}+A_{2 k}-A_{3 k}\right]\left[A_{4 k}+A_{5 k}-A_{6 k}\right]\right\} \\
1(\mathrm{t})= & \frac{d}{d t} L(t) \\
l(t)= & -(1-\rho)\left\{\sum_{k=0}^{\infty}\left\{g_{k}(t)-g_{k+1}(t)\right\}\left[A_{1 k}+A_{2 k}-A_{3 k}\right]+p \sum_{k=0}^{\infty}\left\{g_{k}(t)-g_{k+1}(t)\right\}\left[A_{4 k}+A_{5 k}-A_{6 k}\right]\right. \\
& \left.-p(1-\rho) \sum_{k=0}^{\infty}\left\{g_{k}(t)-g_{k+1}(t)\right\}\left[A_{1 k}+A_{2 k}-A_{3 k}\right]\left[A_{4 k}+A_{5 k}-A_{6 k}\right]\right\}
\end{aligned}
$$

Taking Laplace transform on both sides,

$$
\begin{aligned}
\bar{l}(s)= & -(1-\rho)\left\{\sum_{k=0}^{\infty}\left\{(\bar{g}(s))^{k}-(\bar{g}(s))^{k+1}\right\}\left[A_{1 k}+A_{2 k}-A_{3 k}\right]+p \sum_{k=0}^{\infty}\left\{(\bar{g}(s))^{k}-(\bar{g}(s))^{k+1}\right\}\left[A_{4 k}+A_{5 k}-A_{6 k}\right]\right. \\
& \left.-p(1-\rho) \sum_{k=0}^{\infty}\left\{(\bar{g}(s))^{k}-(\bar{g}(s))^{k+1}\right\}\left[A_{1 k}+A_{2 k}-A_{3 k}\right]\left[A_{4 k}+A_{5 k}-A_{6 k}\right]\right\}
\end{aligned}
$$

It can be shown that distribution function G(.) of the inter exit times satisfy the relation

$$
2 G(x)=\sum_{n=1}^{\infty}\left(1-q_{A}\right)^{n-1} q_{A} F_{n}(x)+\sum_{n=1}^{\infty}\left(1-q_{B}\right)^{n-1} q_{B} F_{n}(x) \text {--- (13) }
$$

where inter decision times follows independent and identically distributed random variables with probability density function $\mathrm{f}($.$) , distribution function \mathrm{F}($.).

$$
\begin{aligned}
& 2 \bar{g}(s)=q_{A} \sum_{n=1}^{\infty}\left(1-q_{A}\right)^{n-1}(\bar{f}(s))^{n}+q_{B} \sum_{n=1}^{\infty}\left(1-q_{B}\right)^{n-1}(\bar{f}(s))^{n}, \\
& \bar{g}(s)=\frac{1}{2}\left\{\frac{q_{A} \bar{f}(s)}{1-\bar{q}_{A} \bar{f}(s)}+\frac{q_{B} \bar{f}(s)}{1-\bar{q}_{B} \bar{f}(s)}\right\}---(14)
\end{aligned}
$$

$\therefore \bar{g}(0)=1$ and $\bar{g}^{\prime}(0)=\frac{-1}{2 \alpha q_{A} q_{B}}$

Note that $\quad E\left(T^{r}\right)=(-1)^{r}\left[\frac{d^{r}}{d s^{r}} \bar{l}(s)\right]_{s=0}, r=1,2, \ldots \quad--(16)$

$$
\begin{aligned}
& E(T)=\frac{(1-\rho)}{2 \alpha q_{A} q_{B}}\left\{\sum_{k=0}^{\infty}\left[A_{1 k}+A_{2 k}-A_{3 k}\right]+p \sum_{k=0}^{\infty}\left[A_{4 k}+A_{5 k}-A_{6 k}\right]-p(1-\rho) \sum_{k=0}^{\infty}\left[A_{1 k}+A_{2 k}-A_{3 k}\right]\left[A_{4 k}+A_{5 k}-A_{6 k}\right]\right\} \\
& \text {--- (17) }
\end{aligned}
$$

This equation (17) gives mean time to recruitment. 
Case - (ii):

$Y=\min \left(Y_{A}, Y_{B}\right) \& Z=\min \left(Z_{A}, Z_{B}\right)$.

$\mathrm{Y}=\min \left(\mathrm{Y}_{\mathrm{A}}, \mathrm{Y}_{\mathrm{B}}\right)$ Where $\mathrm{Y}_{\mathrm{A}}, \mathrm{Y}_{\mathrm{B}}$ are independent and identically distributed exponential random variable with mean $\frac{1}{\lambda_{A}} \& \frac{1}{\lambda_{B}}$ respectively, and the probability density function $\mathrm{h}(\mathrm{y})$ of $\mathrm{Y}$ is given by

$h(y)=\left(\lambda_{A}+\lambda_{B}\right) e^{-\left(\lambda_{A}+\lambda_{B}\right) y}$

Using (4) \& (18) in (5),

$P\left(S_{k}<Y\right)=\int_{0}^{\infty}(1-\rho) \sum_{i=0}^{\infty} \frac{(k \rho)^{i} \phi(k+i, y / b)}{(1-\rho+k \rho)^{i+1}(k+i-1) !}\left[\left(\lambda_{A}+\lambda_{B}\right) e^{-\left(\lambda_{A}+\lambda_{B}\right) y}\right] d y$

$P\left(S_{k}<Y\right)=(1-\rho)\left[A_{3 k}\right]$

Proceeding as in the deviation of $\mathrm{z}$, we find that

$P\left(S_{k}<Z\right)=(1-\rho)\left[A_{6 k}\right]$

Where $A_{3 k}=\frac{1}{\left(b\left(\lambda_{A}+\lambda_{B}\right)+1\right)^{k-1}\left[(1-\rho+k \rho)\left(b\left(\lambda_{A}+\lambda_{B}\right)+1\right)-k \rho\right]}, \&$

$A_{6 k}=\frac{1}{\left(b\left(\mu_{A}+\mu_{B}\right)+1\right)^{k-1}\left[(1-\rho+k \rho)\left(b\left(\mu_{A}+\mu_{B}\right)+1\right)-k \rho\right]}$,

Using (19) \& (20) in (3),

$P(T>t)=\sum_{k=0}^{\infty}\left\{G_{k}(t)-G_{k+1}(t)\right\}(1-\rho)\left[A_{3 k}\right]+p \sum_{k=0}^{\infty}\left\{G_{k}(t)-G_{k+1}(t)\right\}\left[1-\left\{(1-\rho)\left[A_{3 k}\right]\right\}\right]\left[(1-\rho)\left[A_{6 k}\right]\right]$

Now,

$\mathrm{L}(\mathrm{t})=1-\mathrm{P}(\mathrm{T}>\mathrm{t})$

$L(t)=-(1-\rho)\left\{\sum_{k=0}^{\infty}\left\{G_{k}(t)-G_{k+1}(t)\right\}\left[A_{3 k}\right]+p \sum_{k=0}^{\infty}\left\{G_{k}(t)-G_{k+1}(t)\right\}\left[A_{6 k}\right]-p(1-\rho) \sum_{k=0}^{\infty}\left\{G_{k}(t)-G_{k+1}(t)\right\}\left[A_{3 k}\right]\left[A_{6 k}\right]\right\}$

Differentiate and taking Laplace transform on both sides,

$$
\begin{gathered}
\bar{l}(s)=-(1-\rho)\left\{\sum_{k=0}^{\infty}\left\{(\bar{g}(s))^{k}-(\bar{g}(s))^{k+1}\right\}\left[A_{3 k}\right]+p \sum_{k=0}^{\infty}\left\{(\bar{g}(s))^{k}-(\bar{g}(s))^{k+1}\right\}\left[A_{6 k}\right]\right. \\
\left.-p(1-\rho) \sum_{k=0}^{\infty}\left\{(\bar{g}(s))^{k}-(\bar{g}(s))^{k+1}\right\}\left[A_{3 k}\right]\left[A_{6 k}\right]\right\}
\end{gathered}
$$

By using (15) \& (22) in (16),

$$
E(T)=\frac{(1-\rho)}{2 \alpha q_{A} q_{B}}\left\{\sum_{k=0}^{\infty}\left[A_{3 k}\right]+p \sum_{k=0}^{\infty}\left[A_{6 k}\right]-p(1-\rho) \sum_{k=0}^{\infty}\left[A_{3 k}\right]\left[A_{6 k}\right]\right\}
$$

This equation (23) gives the mean time to recruitment

\section{Case(iii):}

$\mathrm{Y}=\mathrm{Y}_{1}+\mathrm{Y}_{2} \& \mathrm{Z}=\mathrm{Z}_{1}+\mathrm{Z}_{2}$

$h(y)=\left[\lambda_{A} /\left(\lambda_{A}-\lambda_{B}\right)\right] e^{-\lambda_{B} y}-\left[\lambda_{B} /\left(\lambda_{A}-\lambda_{B}\right)\right] e^{-\lambda_{A} y}$

Using (4) \& (24) in (5) 
$P\left(S_{k}<Y\right)=(1-\rho)\left[B_{2 k}-B_{1 k}\right]$

Where $B_{1 k}=\left[\lambda_{B} / \lambda_{A}\left(\lambda_{A}-\lambda_{B}\right)\right] A_{1 k} \& B_{2 k}=\left[\lambda_{A} / \lambda_{B}\left(\lambda_{A}-\lambda_{B}\right)\right] A_{1 k}$

$P\left(S_{k}<Z\right)=(1-\rho)\left[B_{5 k}-B_{4 k}\right]$

where

$$
B_{4 k}=\left[\mu_{B} / \mu_{A}\left(\mu_{A}-\mu_{B}\right)\right] A_{4 k} \& B_{5 k}=\left[\mu_{A} / \mu_{B}\left(\mu_{A}-\mu_{B}\right)\right] A_{5 k}
$$

$$
\begin{gathered}
\bar{l}(s)=-(1-\rho)\left\{\sum_{k=0}^{\infty}\left\{(\bar{g}(s))^{k}-(\bar{g}(s))^{k+1}\right\}\left[B_{2 k}-B_{1 k}\right]+p \sum_{k=0}^{\infty}\left\{(\bar{g}(s))^{k}-(\bar{g}(s))^{k+1}\right\}\left[B_{5 k}-B_{4 k}\right]\right. \\
\left.-p(1-\rho) \sum_{k=0}^{\infty}\left\{(\bar{g}(s))^{k}-(\bar{g}(s))^{k+1}\right\}\left[B_{2 k}-B_{1 k}\right]\left[B_{5 k}-B_{4 k}\right]\right\}
\end{gathered}
$$

Using (25), (26), (27) in (15)

$$
E(T)=\frac{(1-\rho)}{2 \alpha q_{A} q_{B}}\left\{\sum_{k=0}^{\infty}\left[B_{2 k}-B_{1 k}\right]+p \sum_{k=0}^{\infty}\left[B_{5 k}-B_{4 k}\right]-p(1-\rho) \sum_{k=0}^{\infty}\left[B_{2 k}-B_{1 k}\right]\left[B_{5 k}-B_{4 k}\right]\right\}
$$

This equation(28) gives the mean time to recruitment

\section{Remark:-}

Computation of $\mathrm{E}(\mathrm{T})$ for extended exponential and SCBZ property possessing thresholds is similar for both the cases as their distribution will have just additional terms.

\section{Findings:-}

From the above results, the following observation are presented which agree with reality.

As $\alpha$ increases, on the average, the inter-decision time decreases and consequently the mean of time to recruitment decreases when the other parameters are fixed.

\section{Conclusion:-}

The models discussed in this paper are found to be more realistic and new in the context of considering (i) separate points (exit points) on the time axis for attrition, thereby removing a severe limitation on instantaneous attrition at decision epochs and (ii) associating a probability for any decision to have exit points. From the organization's point of view, our models are more suitable than the corresponding models with instantaneous attrition at decision epochs, as the provision of exit points at which attrition actually takes place, postpone the time to recruitment.

\section{References:-}

1. Bartholomew.D.J.(1973), Stochastic model for social processes, (John Wiley and Sons, New York).

2. Bartholomew. D.J., and Andrew Forbes.F,(1979) Statistical techniques for manpower planning. (John Wiley and Sons,New York, .

3. Devi.A., and Srinivasan.A,(2014) Variance of time to recruitment for single grade manpower system with different epochs for decisions and exits, International Journal of Research in Mathematics and Computations, 2, 23-27.

4. Devi.Aand Srinivasan.A.(2014), A stochastic model for time to recruitment for a single grade manpower system with different epochs for decisions and exits having inter-decision times as geometric process, Second International Conference on Business Analytics and Intelligence, (ICBAI ).

5. Esther Clara. J.B.(2012), Contributions to the study on some stochastic models in manpower planning, Bharathidasan University, Tiruchirappalli.

6. Girnold.R.C., and Marshall.K.T.(1977), Manpower planning models, (North-Holland, New York).

7. Gurland J.(1955), "Distribution of Maximum of the Arithmetic Mean Correlated random variables". Ann. Math. Statist. (26), 294-300. 
8. Ishwarya .G., and Srinivasan.A.(2015),Time to recruitment in a Two Graded Manpower System with different pochs for Decisions and Exits, International Journal of Science, Technology and Management,4(3), 1- 10.

9. Ishwarya .G., and Srinivasan A.(2015), Time to recruitment in a Two graded Manpower System with correlated Inter- decision times and independent Inter-exit times , International Journal of Applied Engineering Research, 10(5),12929-12938.

10. Parameswari.K., Sridharan.J., and Srinivasan.A.(2013), Stochastic model on time to recruitment in a two graded manpower system, Proceedings of National conference on Recent Advances in Mathematical Analysis and Applications, 378-387.

11. Ravichandran.G., andSrinivasan.A.(2015), Variance of time to recruitment for a single grade manpower system with two thresholds having different epochs for decisions and exits, Indian Journal of Applied Research $5(1), 60-64$.

12. Ravichandran.G., andSrinivasan.A.(2015), Time to recruitment for a single grade manpower system with two thresholds, different epochs for exits and Geometric inter-decisions, IOSR Journal of Mathematics, 11(2),Ver. III, 29-32.

13. Saral.L.,Sendhamizhselvi.S., and Srinivasan.A.(2016),Mean Time to Recruitment for a two Graded manpower system with two thresholds, Different Epochs for Exits and Correlated inter-decisions, International Journal of Innovative Science, Engineering \& Technology, 3(10).

14. Saral.L.,Sendhamizhselvi.S., and Srinivasan.A.(2016),Mean Time to Recruitment for a two Graded manpower system with two thresholds, Different Epochs for Exits and Two types of inter-decisions, International Journal of Innovative Research in Science, Engineering \& Technology,5(11).

15. Srinivasan, A., and Vasudevan, V.(2011), Variance of the time to recruitment in an Organization with two grades, Recent Research in Science and Technology, 3(1),128-131. 